\title{
AN INNOVATIVE TECHNIQUE FOR HOLLOWING A PROSTHESIS WITH EXCESSIVE VERTICAL HEIGHT USING POLYVINYL SILOXANE PUTTY
}

\author{
Nitasha Gandhi ${ }^{1}$, Nirmal Kurian², Supneet Singh Wadhwa ${ }^{3}$, Angleena Daniel ${ }^{4}$, Smitha Daniel $^{5}$, Vinaya Susan Varghese ${ }^{6}$ \\ ${ }^{1}$ Professor and Head, Department of Prosthodontics And Crown And Bridge, Christian Dental College, Punjab, India \\ ${ }^{2}$ PG Student, Department of Prosthodontics And Crown And Bridge, Christian Dental College, Punjab, India \\ ${ }^{3}$ Assistant Professor, Department of Prosthodontics And Crown And Bridge, Christian Dental College, Punjab, India \\ ${ }^{4}$ Associate Professor, Department of Prosthodontics And Crown And Bridge, Christian Dental College, Punjab, India \\ ${ }^{5}$ PG Student, Department of Prosthodontics And Crown And Bridge, Christian Dental College, Punjab, India \\ ${ }^{6}$ PG Student, Department of Conservative and Endodontics, Maratha Mandal Dental College, Karnataka, India
}

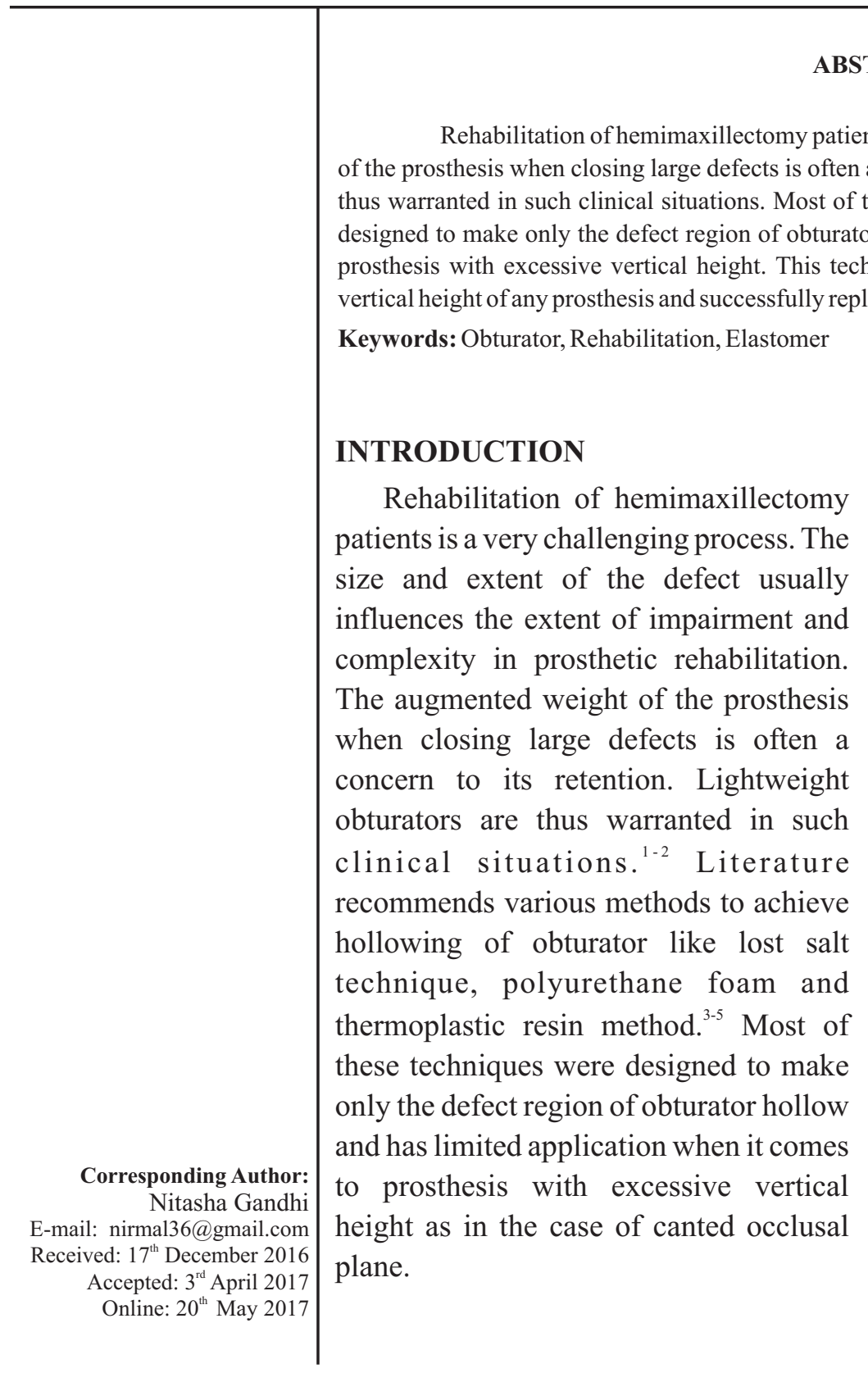

Keywords: Obturator, Rehabilitation, Elastomer the augmented weight of the prosthesis when closing large defects is often a concern to its retention and lightweight obturators are thus warranted in such clinical situations. Most of the techniques in literature to hollow a prosthesis were designed to make only the defect region of obturator hollow and has limited application when it comes to prosthesis with excessive vertical height. This technique described in this article can be used to hollow vertical height of any prosthesis and successfully replace conventional techniques when they are not feasible.

\section{Clinical Report}

A 45-year-old woman reported to the Department of Prosthodontics, Christian Dental College, CMC Ludhiana for the rehabilitation of maxillary defect after hemimaxillectomy. Intraoral examination revealed an Aramany's Class I maxillectomy defect on the left side with a canted occlusal plane. (Figure 1a) Degree and character of defect and bony margins prevented an obturator design which could derive retention from extention of bulb portion of prosthesis into defect. Canted occlusal plane meant excessive vertical height of proposed prosthesis over the defect region which had to be hollow to minimize the weight of prosthesis. Compromised circumstances and inability of established techniques to make the vertical portion of prosthesis hollow led to conception of a novel laboratory technique. This article describes an innovative technique of 
fabrication of hollow prosthesis when conventional techniques are not feasible.

\section{Technique}

1. A definitive impression of the maxillary residual ridge and defect region was made and the denture was fabricated to the trial denture stage. (Figure $1(b, c))$

2. After wax try-in with proper evaluation of speech, function and esthetics duplication of the trial denture in reversible hydrocolloid was done and impression was poured in dental stone.

3. A clear template of duplicated stone cast using thermoplastic sheet was made. (Figure 2(a))

4. Flasking and de-waxing of the obturator prosthesis cast was done. Upper compartment of the flask was separated and kept aside to be used at a later stage.

5. A layer of modeling wax was adapted on the tissue surface of the master cast which was still in lower part of original flask
6. Flasking of lower part of original flask with upper component of new flask assembly was completed.

7. De-waxing, packing and acrylization with heat cure acrylic resin were carried out to get a master cast with acrylic resin layer covering the residual regions and defect region. (Figure 2 (b))

8. The previously obtained clear thermoplastic matrix was positioned on the definitive cast. An endodontic file with a rubber stop was used to measure the space between the matrix and the processed resin.

9. Vinyl polysiloxane putty was mixed and adapted to the bur-roughened acrylic resin and shaped to the approximate contours of the matrix.

10. Polymerized putty was molded to leave $2-3 \mathrm{~mm}$ of space between the putty and matrix for heat cure acrylic. An additional 1-mm space over the tooth
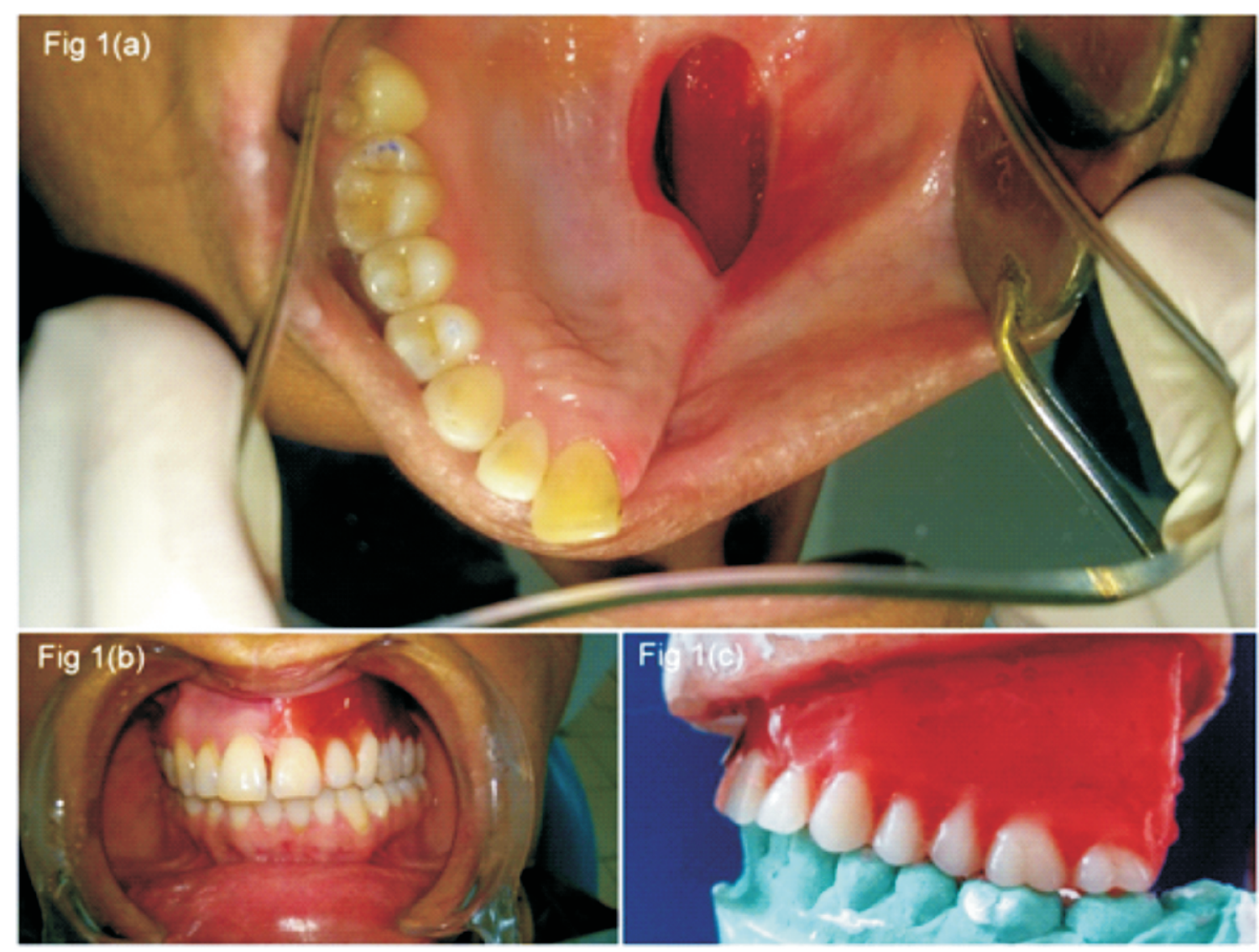

Figure 1(a) Intraoral view of Aramany's Class I maxillectomy 1(b,c) Wax try in 


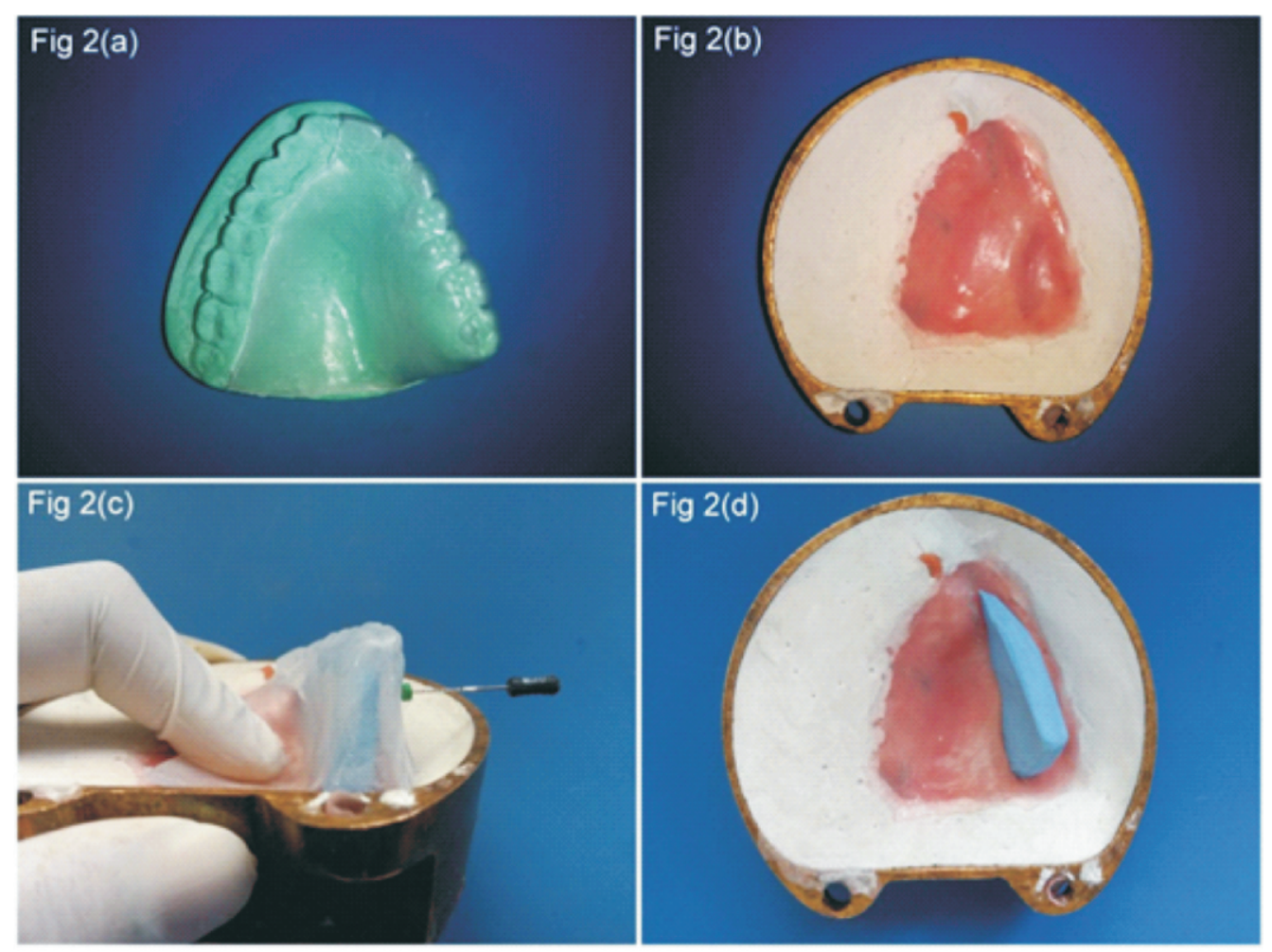

Figure 2(a) Clear template of duplicated stone cast 2(b) Master cast with acrylic resin layer covering the residual regions and defect region $2(\mathrm{c}, \mathrm{d})$ Adjusted putty fixed to the already processed acrylic resin

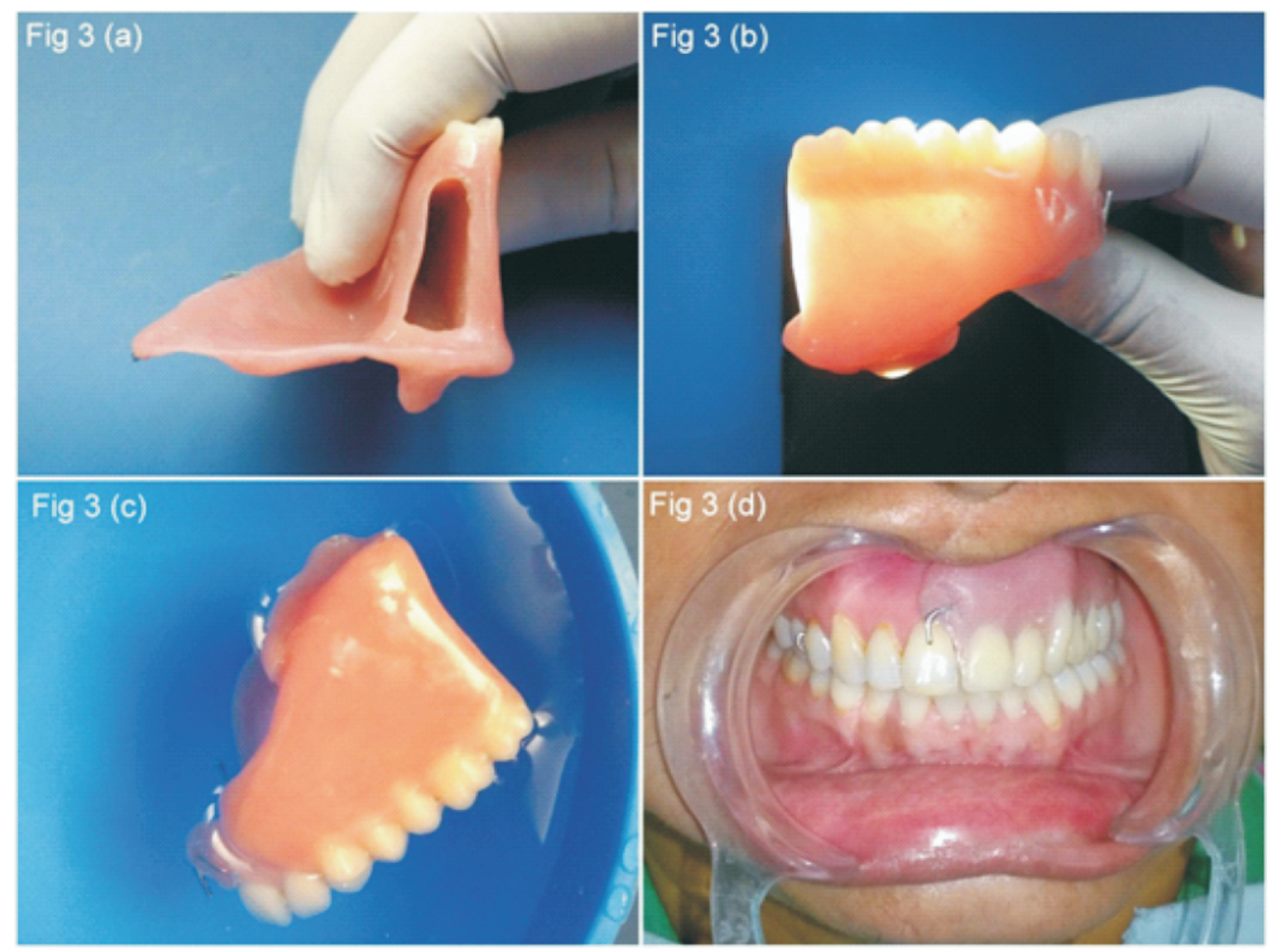

Figure 3(a) Silicone putty removed through access holes 3(b,c) Floating of prosthesis indicated light weight of prosthesis Fig 3(d) Final prosthesis 
portion of the denture was provided.

11. Confirmation of the space was done with the help of endodontic file with a rubber stop. The adjusted putty was fixed to the already processed acrylic resin using cyanoacrylate. (Figure $2(\mathrm{c}, \mathrm{d})$ )

12. The original upper portion of the flask was reseated on the part with processed acrylic and silicone putty and verification of fit of cast was done. The heat cure acrylic resin was mixed mixed, packed and polymerized. The processed denture was recovered in the usual manner.

13. Two openings were cut with a bur into the denture base distal to the most posterior teeth. The silicone putty was removed by scraping with a sharp instrument and the access channel holes were closed using autopolymerizing resin (Figure 3 (a)).

14. The denture was finished and polished in the usual manner. Verification of seal was done by immersing the denture in water to rule out bubbles. Floating of prosthesis indicated light weight of prosthesis. (Figure 3. (b-d)

\section{DISCUSSION}

Hollow obturators are fundamental in rehabilitation of post maxillectomy defects to lighten the weight which will contribute to overall retention, stability and success of the prosthesis. Several techniques and materials have been described previously to fabricate a lightweight hollow obturator, which includes grinding the interior surface of bulb, fastening superior border of hollow space with a lid, use of sugar or ice in processed resin. ${ }^{6-9}$ Two step processing technique using preformed plastic shapes, plaster matrix, polyurethane foam or acrylic shims were tried by various authors, but none of the above mentioned techniques can be used to obtain predictable internal dimension of the hollow space within the vertical portion of prosthesis as in the case of can $t e d$ occlusion or severe bone loss. The technique described helps to overcome the impracticality of conventional technique by using silicone putty material which because of its solid structure can be used in laboratory phase to generate space within the plaster mould. The potential of silicone putty to form multidimensional space within the plaster mould can be used to hollow out prosthesis of any design. Application of this technique can be expanded to complete denture cases with severe bone loss necessitating excessive vertical height of denture. ${ }^{10}$ Advantages of silicone putty technique are the utilization of readily available materials and being efficient and foolproof at the same time. Laboratory steps are technique sensitive demanding precision and judgement from the operator/technician which is a limitation of this technique. The ability of this technique to provide a predictable internal dimension of hollow space to achieve uniform wall thickness even in the vertical component of prosthesis in one-step processing procedure justifies its novelty.

\section{CONCLUSION}

This article describes a technique for fabricating a hollow prosthesis with excessive vertical height. The technique uses a clear matrix of trial denture to facilitate shaping of a silicone putty spacer ensuring significant reduction in weight of prosthesis. This technique can be used to hollow vertical height of any prosthesis and successfully replace conventional techniques when they are not feasible.

\section{REFERENCES}

1. Kornblith AB, Zlotolow IM, Gooen J, Huryn JM, Lerner T, Strong EW el. Quality of life of maxillectomy patients using an obturator prosthesis. Head Neck 1996;18:323-34

2. Wu YL, Schaaf NG. Comparison of weight reduction in different designs of solid and hollow obturator prostheses. J Prosthet Dent 1989;62:214-7

3. Brown KE. Clinical considerations improving obturator treatment. J Prosthet Dent 1970;24:461-6.

4. Birnbach S, Barnhard B. Direct conversion of a solid obturator to a hollow obturator prosthesis. J Prosthet Dent 1989;62:58- 
60

5. Parel SM, LaFuente H. Single-visit hollow obturators for edentulous patients. J Prosthet Dent 1978;40:426-9

6. Minsley GE, Nelson DR, Rothenberger SL. An alternative method for fabrication of a closed hollow obturator. J Prosthet Dent 1986;55:485-90

7. Habib BH, Driscoll CF. Fabrication of a closed hollow obturator.J Prosthet Dent 2004;91:383-5
8. Kocacikli M, Yalug S, Yazicioglu H, Yilmaz C. Fabricating a hollow obturator with visible light-cured resin system. J Prosthodont 2008; 17:596-8

9. Patil P G, Patil S P, A Hollow definitive obturator fabrication technique for management of partial maxillectomy, J Adv Prosthodont 2012;4:248-53

10. Michael O'Sullivan, Nancy Hansen, Robert J. Cronin, and David R. Cagna. The hollow maxillary complete denture: A modified technique, J Prosthet Dent 2004;91:591-4. 